\title{
KAJIAN PSIKOALISIS DALAM NOVEL CINTA TAK PERNAH TEPAT WAKTU KARYA PUTHUT EA
}

\author{
Meli Kusmawati \\ Pendidikan Bahasa Indonesia, Universitas Muhammadiyah Mataram, Indonesia \\ melikusmawati@gmail.com
}

\begin{tabular}{l}
\hline \hline INFO ARTIKEL \\
\hline Riwayat Artikel: \\
Diterima: $22-10-2018$ \\
Disetujui: $20-01-2019$ \\
\end{tabular}

Kata Kunci:

Psikoanalisis, Jacques Lacan, Cinta Tak Pernah

Tepat Waktu, Puthut EA

\begin{abstract}
ABSTRAK
Abstrak: Penulisan ini untuk mengetahui tokoh Aku yang mengalami luka karena dikhianati dan ditinggalkan oleh kekasihnya sehingga ia mengalami konflik batin. Pembaca diberi gambaran untuk terus berjalan meskipun deretan ironi telah banyak melukai. Novel ini memiliki aspek-aspek yang sangat menarik untuk dikaji. Masalah yang dibahas dalam penelitian ini adalah bagaimana aspek-aspek prikoanalisi (yang nyata, yang imajiner, dan yang simbolik)dAalam Novel Cinta Tak Pernah Tepat Waktu karya Puthut EA . Berdasarkan rumusan masalah tersebut, penelitian ini bertujuan untuk mendeskripsikan aspek-aspek psikoanilisis yang terdapat dalam Novel Cinta Tak Pernah Tepat Waktu karya EA. Jenis penelitian ini adalah penelitian kualitatif untuk menghasilkan data berupa berupa deskriptif. Metode yang digunakan dalam pengumpulan data antara lain: metode dokumentasi, metode telaah, dan metode studi perpustakaan. Sesuai terkumpul akan dianalisis dengan tekhnik deskriptif. Hasil penelitian ini adalah novel Cinta Tak Pernah Tepat Waktu karya Puthut EA mengandung aspek-aspek psikoanalisi. Aspek-aspek psikoanalisis yang terdapat dalam novel ini dibagi menjadi tiga, yaitu: yang nyata(rasa kenyamanan pada tokoh Aku) yang imajiner (rasa kehilangan pada tokoh Aku), yang simbolik (rasa keinginan pada tokoh Aku)Setiap karya sastra pada dasarnya mengandung aspek-aspek yang dapat memberikan manfaat sebagai pedoman bagi pembacanya sehingga hendaknya karya-karya sastra dapat diapresiasikan secara maksimal. Novel ini berisi pengalaman tokoh Aku beserta hikmah yang dapat dipetik dalam kehidupan.
\end{abstract} Abstrak: The writing was to know the figure of I who was injured by being betrayed
and abandoned by his lover so that he suffered an inner conflict. Readers are given an
overview to keep going though a row of irony has hurt a lot. The Novel has very
interesting aspects to be studied. The problem discussed in this study is how the
Prikoanalyisi aspects (the real, the imaginary, and the symbolic) dAalam Novel Love
never punctual the work of Puthut EA. Based on the problem, this research aims to
describe the aspects of psychoanilisis in the Novel Love never-timely work of EA. This
type of research is qualitative research to produce a descriptive form of data. Methods
used in data collection include: Documentation methods, study methods, and library
studies methods. The appropriate collected will be analyzed with descriptive
technology. The results of this research are novel love never timely work by Puthut
EA contains psychoanalyisi aspects. The psychoanalytical aspects contained in the
novel are divided into three, namely: the real (sense of comfort on the figure of me) the
imaginary (the loss of my character), the symbolic (sense of desire on the figure of me)
every literary work essentially Contains aspects that can provide benefits as a
guideline for its readers so that the literary works can be maximally appreciated. This
Novel contains the experience of the character I and the wisdom that can be learned
in life. 


\section{A. LATAR BELAKANG}

Psikologi sastra merupakan salah satu pendekatan dalam memahami karya sastra. Pendekatan itu mempunyai kedudukan yang sama dengan pendekatan-pendekatan yang lain. Menurut Hartoko dan B. Rahmanto (1984: 126-127), psikologi sastra adalah mengkaji sastra dari sudut psikologi, Objek kajian pengarang adalah untuk melihat hubungan antara kreativitas pengarang dan produksi karyanya atau melihat hubungan antara pengarang dan karyanya. Kajian pembaca diarahkan untuk melihat pengaruh karya sastra pada pembaca dan juga bagaimana proses penerimaan karya sastra oleh pembaca (Badrun 2012: 4).

Psikoanalisis dapat digunakan untuk menilai karya sastra karena psikologi dapat menjelaskan proses kreatif. Misalnya, kebiasaan pengarang merevisi dan menulis kembali karyanya. Yang lebih bermanfaat dalam psikoanalisis adalah studi mengenai perbaikan nafkah, koreksi, dan seterusnya. Hal itu berguna karena jika dipakai dengan tepat dapat membantu kita melihat keretakan (fissure), ketidakteraturan perubahan, dan distorsi yang sangat penting dalam suatu karya sastra. Psikoanalisis dalam karya sastra berguna untuk menganalisis secara tidak sadar maupun secara sadar dapat memasukan teori psikologi yang dianutnya.

Barry dalam bukunya Beginning Theory (2010:127) menyebutkan bahwa Jasques Lacan (1901-1981) adalah psikoanalisi prancis yang karyanya memiliki pengaruh luar biasa pada banyak aspek dalam teori sastra belakang ini. Lacan memulai karirnya dengan mendapat gelar di bidang kedokteran dan kemudian menjalani pelatihan psikiatri ditahun 1920-an. Lacan terkenal dengan teorinya struktur ketidaksadaran manusia yang menyerupai bahasa. Ia dianggap dari penggunaan bahasa. Teorinya mengenai psikologi ini merupakan bentuk pengembangan diri dari teori Freud yang sebelumnya terkonsentrasi pada aspek ketidaksadaran manusia.

Dalam teori phalic stage yang digagaskan oleh Freud bahwa perkembangan psikologi manusia berkembang seiring dengn berkembangnya seksualitas dari manusia tersebut (Bakar dalam Gajarjati, 2007:115-116). Lacan kemudian merangkumkan hal serupa, namun dengan menggunakan konsep yang berbeda. Teori pembentukan diri dari Lacan ini hampir mirip dengan apa yang dirumuskan oleh Freud, menurut Lacan, pengalaman perkembangan manusia ada pada tahap-tahap tertentu yang dikenal dengan tripartite model, yaitu; 'yang nyata (the real), 'yang Imajiner (the imajinery) ; dan 'yang simbolik (the symbolic) ; lintasan fase-fase ini oleh Lacan dipertemukan dengan konsep kebutuhan (need) permintaan (demand) dan hasrat (desire).

Karya sastra adalah objek manusiawi, fakta kemanusiaan, atau fakta faktural, sebab merupakan hasil ciptaan manusia Meskipun demikian, karya itu mempunyai eksistensi yang khas membedakanya dari fakta kemanusiaan lainya seperti sistem sosial dan sistem ekonomi dan yang menyamakanya dengan sistem seni rupa, seni suara, dan sebagainya. Kalau sistem lainya seringkali dianggap sebagai satuan yang dibangun oleh hubungan antar tindakan, karya sastra merupakan satuan yang dibangun atas hubungan antara tanda dan makna, antara ekspresi dengan pikiran, antara aspek luar dengan aspek dalam (Faruk, 2012:77).

Novel adalah proses prosa rekaan yang menyuguhkan tokoh dan menampilkan serangkaian peristiwa serta latar secara tersusun. Novel sebagai karya imajinatif mengungkapkan aspek-aspek kemanusiaan yang mendalam dan menyajikanya secara halus. Novel tidak hanya sebagai alat hiburan, tetapi juga sebagai bentuk seni yang memepelajari dan meneliti segi-segi kehidupan dan mengarahkan pada pembaca tentang budi pekerti yang luhur (Sudjiman, 1998:53)

Novel Cinta Tak Pernah Tepat Waktu karya Puthut EA ini mengisahkan seorang tokoh "Aku”yang terjebak dalam kisah cintanya yang suram. Ia terus melangkah, berusaha menyembuhkan lukanya dan berharap luka itu bisa sembuh sebelum dia memulai sesuatu yang baru. Novel ini juga menceritakan tentang tokoh "Aku"dengan pergolakan pemikiranya, goncangan batin pencarian cinta, dan upaya menyembuhkan luka.

Analisis novel dengan menggunakan ilmu psikologi menjadi menarik untuk membedah karya sastra dikarenakan di dalam ilmu psikologi terdapat kajian ilmu psikoanalisis yang mempunyai ikatan erat dengan karya sastra. Psikoanalisis adalah wilayah kajian psikoanalisis sastra yang menganalisis secara terperinci.

Pengalaman emosional yang dapat menjadi sumber atau sebab gangguan jiwa tokohnya (Hariwijaya 2009:41) Dengan kata lain, pendekatan psikoanalisis dalam realita kehidupan manusia berupa tingkah laku, emosional, intelektual dan mental yang terjadi dalam lehidupan sehari-hari. Jadi novel sangatlah penting untuk dianalisis sebagai bentuk penilaian mutu dari karya sastra dalam menghasilkan suatu analisis yang mendalam berdasarkan kajian psikonalisis pada Novel Cinta Tak Pernah Tepat Waktu karya Puthut EA merupakan novel yang di dalamnya terdapat nilai psikoanalisis yang terjadi pada tokoh Aku dalam cerita. Nilai psikoanalisis itu tergambarkan dalam 
percakapan baik dialog maupun monolog dalam novel.

Rencangan penelitian yang digunakan dalam penelitian ini, yang pertama dilakukan oleh peneliti adalah menentukan obejek material, sebagai bahan penelitian yaitu novel Cinta Tak Prrnah Tepat Waktu karya Puthut EA. telah menentukan objek material dan pembacaan menyeluruh terhadapo novel kemudian menemukan hal-hal yang menarik untuk diteliti, lalu menentukan teori yang duigunakan untuk memecahkan masalah tersebut.

Penggunaan metode ini adalah penelitian yang dalam pelaksanaanya menggambarkan bahwa data yang diperoleh yaitu data yang menggambarkan fakta yang ada dalam Novel mengenai aspek psikoanalisis Jacques Lacan dalam Novel Cinta Tak Pernah Tepat Waktu karya Puthut Ea. Selain itu, penelitian kulitatif dapat diartikan sebagai prosedur penelitian yang menghasilkan data deskriptif berupa kata-kata tertulis atau lisan dari orang-orang dn perilaku yang dapat diamati (Molong, 2001:3)

\section{B. METODE PENELITIAN}

\section{Data}

Data adalah catatan keterangan sesuai bukti dan kebenaran, bahan-bahan yang dipakai sebagai dukungan penelitian. Data dalam penenlitian ini adalah data kulalitatif yaitu data yang menggambarkan fakta yang ada dalam Novel mengenai aspek-aspek Psikoanalisis Jasques Lacan dalam Novel Cinta Tak Pernah Tepat Waktu karya Puthut EA.

\section{Sumber Data}

Sumber data terkait dengan subjek penelitian dari mana data diproleh. subjek penelitian sastra adalah konteks ini adalah teks-teks novel Siswantoro, 2010:72) Sumber data dalam penelitian ini adalah novel Cinta Tak Pernah Tepat Waktu karya Puthut EA. Berikut ini identitas novel tersebut.
a. Judul Novel: Cinta Tak Pernah Tepat Waktu
b. Pengarang: Puthut EA
c. Penerbit: Mojok
d. Tempat terbit: Yogyakarta
e. Jumlah halaman : 225
f. Jenis buku: novel
g. Cetakan: ke-7

Aspek psikoanalisis Jasquen Lacan dalam Novel Cinta Tak Pernah Tepat Waktu karya Puthut EA dialog dan monolog ditunjukkan dalam dekskripsi cerita, dialog maupun monolog tokoh dalam menyikapi suatu masalah. Dalam novel ini terdapat dialog dan monolog seperti percakapan pada umumnya. Namun percakapan ini berbentuk tulisan sehingga lebih mudah untuk dilihat dan dibaca berulang-ulang.

Paragraf dan kalimat dalam sebuah novel merupakan kumpulin ide yang ingin dituangkan oleh pengarang, Interpretasi yang berbeda-beda dapat timbul karena berbedanya kemampuan pembaca untuk melihat dan menilai lebih dalam isi dari sebuah novel dan pesan ingin disampaikan oleh pengarang terkadang dipahami

\section{Metode Dokumentasi}

Metode dokumentasi merupakan catatan, peristiwa yang sudah berlalu. Dokumen berbentuk tulisan, gambar, atau karya-karya monumentaldari seseorang(Sugiyono, 2014:240)

Metode dokumentasi ini digunakan untuk mencari data secara sisetematisuntuk memudahkan pemahaman peneliti tentang objek yang akan diteliti. Dimulai dengan menelaah dan mengumpulkan semua data yang terdapat dalam novel Cinta Tak Pernah Tepat Waktu karya Puthut EA.

\section{Metode Telaah}

Metode telaah merupakan metode pengumpulan data dengan cara mencari teori-teori konsep. generalisasi-generalisasi yang dapat dijadikan landasan teoritas bagi penelitian yang akan dilakukan (Khaeruddin dan Akib, 2009:45)

Metode telaah ini digunakan untuk mendalami dan menganalisis data-data tertulis dalam novel Cinta Tak Pernah Tepat Waktu karya Puthut EA yang menjadi objek peneliti.

Berbeda-beda oleh pembaca. Oleh karena itu, paragraf dan kalimat yang jelas akan lebih mudah dipahami pembaca. Pesan yang ingin disampaikan oleh pengarang pun dapat dipahami dengan mudah oleh pembaca. Untuk melihat pembaca dibalik deksripsi cerita dalam skripsi ini, peneliti menyajikanya dalam bentuk kutipan kalimat dan paragraf.

\section{Metode Studi Kepustakaan}

Studi kepustakaan berkaitan dengan kajian teoritas dan referensi lain yang yang berkaitan dengan lain, budaya, dan norma yang berkembang pada situasisosial yang diteliti, selain itu studi kepustakaan sangat penting dalam melakukan penelitian, hal ini dikarenakan penelitian tidak akan lepas dari literature-literatur ilmiah (Sugiyono, 2012:291)

Sumber kepustakaan yang dimaksud adalah bukubuku teori sastra, metodologi penelitian, dan bukubuku yang ada kaitanya dengan penelitian yang dilakukan.

\section{Metode Analisis Data}

Metode analisis data merupakan suatu cara atau teknik untuk mengelola data yang telah 
dikumpulkan dengan tujuan bisa menjawab pertanyaan penelitian.

Metode yang digunakan dalam menganalisis data adalah metode deskriptif kualitatif intrerpretatif.

Menurut Ratna (2010:45) metode deskriptif kualitatif interpretative yaitu sebuah metode penelitian yang membahas mengenai konsep teoritik yang mengarah kepada tindakan, penutur manusia dan lingkungan sosial budaya.

Metode ini dilihat dari sebuah fakta sebagai sesuatu yang menarik dalam memahami makna.

Penelitian menggunakan deskriptif karena data yng penulis diskripsikan dalam penelitian ini akan digambarkan dengan jata-kata (deskripsi).

Metode analisis data dalam penelitian ini dimkasud yaitu untuk mendeksripsikan data dalam novel Cinta Tak Pernah Tepat Waku Puthut EA.

\section{HASIL DAN PEMBAHASAN}

\section{Sinopsis}

Novel ini memiliki gaya bahasa yang indah dan sederhana. Kekuatan novel ini terletak pada monolog yang dipahami dan ringan untuk dibaca. Novel ini merencanakan tentang kehidupan tokoh Aku yang mengalami luka hati dengan kekasihnya pada zaman kuliahnya.

Kekasihnya itu telah pergi meninggalkanya. sehingga tokoh Aku mengalami luka hati, pikiranya stres, frustasi, kurang makan, kurang tidur dan terpuruk dalam kesendirianya karna kekasihnya telah menghianatinya dan pergi bersama orang lain.

Kekasihnya itu merasa lelah dan sudah tidak kuat lagi untuk menjaga dan merawatnya, karena tokoh Aku sering mengalami kesakitanpada zamanya kuliah, akhirnya kekasihnya itu memutuskan untuk meninggalkanya. dan pergi bersama orang lain.

Setelah ditinggalkan oleh kekasihnya itu, si tokoh Aku mengalami luka dihatinya dan terpuruk dalam harus kesedihan, tidak tahu tidak tau harus berbuat apa, selalu mengurung diri di dalam kamar, tidak ingin menemui siapa-siapa karna takut meluapkan emosinya ketika ada kata-kata yang membuat dirinya tersinggun dan sejak itu iya lebih nyaman berada didalam kamar ketimbang menemui teman-temanya di luat, sering merasakan kesakitan dilahir dan bantin

Tokoh Aku pun mencoba untuk mencari dan menjalin hubungan dengan wanita lain agar bias melupakan kekasihnya itu. Ada beberapa perempuan yang iya dekati, salah satunya perempuan yang ingin dijodohkan orang tuanya dikampung tetapi ada saja halangan sehingga mereka tidak menjadi menikah begitu pula perempuan-perempuan lain ketika iya inggin mmenjalin hubungan yang serius namun waktu selalu tepat baginya. Semua yang iya lakukan untuk mencari pengganti kekasihnya yang dulu itu hanyalah sia-sia baginya, tidak ada yang bias mengerti dengan keadaanya dan perempuanperempuan yang ia cari selama ini tidak ada yang cocok denganya dan ketika cintanya dating selalu tidak tepat pada waktunya.

Akhirnya, ia pun memtuskan untuk berhenti mencari cinta dan memilih untuk menyibukkan diri dengan pekerjaan-pekerjaan yang bermanfaat dan mulai me ngerjakan pekerjaan yang bermanfaat bersama teman-temanya dengan cara membangun sebuah komunitas dengan menulis novel, tokoh Aku dengan perlahan-lahan bisa melupakan kekasihnya dan baru menyadari bahwa itu hanya membawanya keterpurukan dan merusak pikiranya saja.

Permasalahan yang alami tokoh Aku ini, dikendalikan oleh dirinya sendiri sehingga menimbulkan konflik batin yang dialaminya itu sulit untuk diselehsaikan, rtetapi pada akhirnya dari permasalahan tokoh Aku menemukan jalan keluarnya untuk menyembuhkan luka hati yang dialaminya.

\section{Aspek-aspek psikoanalisi dalam Novel "Cinta Tak Pernah Tepat Waktu"karya Puthut EA.}

Pendekatan psikoanalisis yang banyak bersadar kepada psikoanalisis yang dikembangkan Fread setelah melakukan berbagai, penelitian, bahwa manusia banyak dikuasai oleh alam batinya sendiri. Peneliti akan menggunakan teorikehilangan, kecewa, dan terpuruk, sehingga dia lebih memilih untuk merenung, menyendiri didalam kamar, dan tidak ingin menemui orang-orang.

Pengaruh dari yang Imajiner yang terjadi pada tokoh Aku dalam Novel Cinta Tak Pernah Tepat Waktu karya Puthut EA yaitu adanya rasa kehilangan, kekecewaan, dan terpuruk dan kisah cintanya yang berakhir kandas. Makanya dalam cerita sering kali ditemukan tokoh Aku yang merasa kecewa, terpuruk, dan frustasi.

\section{Rasa Keinginan pada Tokoh Aku}

Setiap manusia pasti mempunya rasa keinginan terhadap sesuatu, munculnya rasa keinginan pada diri manusia karena merasa ada yang kurang dalam dirinya, Dalam Jasquen Lacan, yang simbolik ditandai dengan rasa keinginan yang ada pada diri sang anak, yang dimana sang anak mulai merasukinya terhadap sesuatu. Sama seperti keadaan si Tokoh Aku dalam Novel Cinta Tak Pernah Tepat Waktu Puthut EA, tokoh Aku mempunyai keinginan dalam hal melupanya dan ingin bangkit dari kisah cintanya yang suram, dengan cara menyibukkan diri dengan kegiatan atau aktivitas yang bermanfaat yaitu membangun komunitas alternative bersama teman-temanya dalam hal membuat buku, novel dan menambah kegiatan 
dengan usaha warnet dan penerbit buku, dipenuhi namun tidak dapat terpuaskan, karena kita dibawa kea rah suatu "kekurangan"(tack)Ketikaa sang anak tahu tubuhnya terpisah dari ibunya dan dunia, maka ia mulai cemas, karena merasa ada suatu yang hilang. Tuntutan anak adalah menjadikan yang lain bagian dirinya, sehingga sang anak tidak lagi berada dalam"kodisi alami". Tuntutan yang tidak terpenuhi menimbulkan ingatan akan"kehilangan"dan "kekurangan"

\section{Yang Simbolis (The symbolic)}

Bagi Lacan, keinginan bukan merupakan'keinginan'internal individu, tetapi pengalaman yang disituasikan dalam konteks kelainan (otherness). Walaupun keinginan adalah keinginan akan yang lain, api keinginan tidak pernah mencapai objek keinginan.

\section{SIMPULAN DAN SARAN}

Karya sastra yang mengandung aspek-aspek dapat mengandung psikoanalisis agar bisa menyikapi suatu masalah yang terjadi Aspek-aspek psikoanalisis yang terkandung didalamnya untuk mengapresiasi sebuah karya sastra khususnya novel. menjadikan aspek-aspek psikoanalisis tersebut sebagai contoh dalam menjalankan kehidupan sehari-hari. Aspek-aspek psikoalisis yang terdapat dalam novel Cinta Tak Pernah Tepat Waktu karya Puthut EA, sebagai berikut:

1. Yang nyata. Yang nyata adalah suatu wilayah psikis yang belum ada keterpisaha, tidak ada bahadsa, tidak ada kehilanganYang ada hanya adalah pemenuhan utuh dan kesatuan sempurna Wilayah yang nyata pada mulanya dinikmati oleh subjek sebagai sesuatu kondisi yang tidak berkekurangan(pengalaman atau kondisi sebelum subjek terpisah dari kenikmatan tubuh dan rahim sang ibu). Yang nyata, yang terdapat dalam novel Cinta Tak Pernah Tepat karya Phutut EA, yaitu :rasa kenyamanan pada tokoh Aku.

2. Yang imajiner. Yang Imajiner ditandai dengan proses disebut dengan tahap cermin pada tahap cermin subjek beralih dari kebutuhan primer ke tuntutan. Tuntutan sang anak adalah menjadikan yang lainbagian darinya, sehingga sang anak tidak lagi berada Dalam kondisi alami, Tuntutan yang tidak terpenuhi menimbulkan ingatan akan kehilangan dan kekurangan. Yang imajiner, yang terdapat dalam novel Cinta Tak Pernah Tepat Waktu karya Puthut Ea, yaitu:rasa kehilangan pada tokoh Aku
3. Yang simbolik. Yang simbolik ditandai dengan keinginan, Walaupun keinginan adalah keinginan akan yang lain, tetapi keinginan tidak Pernah mencapai objek keinginan, Namun kita tidak dapat melepaskan keinginan diatur oleh sebuah sistem linguistic atau tatanan simbolik. Keinginan terletak dalam kekurangan, karena fantasi tidak pernah bersesuaian dengan segala sesuatu dalam real. Yang simbolik, yang terdapat dalam novel Cinta Tak Pernah Tepat Waktu karya Phutut EA. yaitu keinginan pada tokoh Aku.

Karya sastra dalam hal ini adalah novel merupakan produk masyarakat yang sangat berharga. Oleh karena itu, harus dijaga dan tidak boleh hilang agar para penerus yang akan datang dapat menikmati karya tersebut.

Berdasarkan hasil analisis dan kesimpulan, berikut ini dipaparkan beberapa saran, antara lain:

1. Setiap karya sastra pada dasarnya mengandung aspek-aspek psikoanalisis yang dapat member manfaat sebagai pedoman hidup pembacanya. Sehingga hendaknya karya-karya sastra yang ada diapresiasikan secara maksimal.

2. Hasil penelitian ini diharapkan dapat dijadikan sebagai pedoman dalam menjalani dan menyikapi suatu masalah masalah yang terjadi dalam hidup melalui jalan.

3. Untuk peneliti-penenliti yang lain, diharapkan hasil penelitian ini dapat dijadikan referensi untuk mengkaji kembali tentang aspek-aspek psikoanalisis maupun aspek-aspek lainya yang ada dalam sebuah karya sastra.

4. Penulis berharap agar hasil penelitian ini dapat bermanfaat agar meningkatkan pengetahuan dan wawasan pembaca, khususnya yang berkaitan dengan aspek-aspek psikoanalisis

\section{REFERENSI}

Barry, Peter 2010 Beginning Theory, Jalasutra:Yogyakarta. EA, Puthut. 2005 . Cinta Tak Pernah Tepat Waktu, Mojok: Yogyakarta.

Endaswara, S. 2011. Metedelogi Penelitian Sastra . Jakarta : Caps.

Evasari. 2014 Analisis Novel "Emak, Aku Minta Surgamu, Ya..."Karya Taufiqqurahman Al-Azizy Sebuuh kajian Psikologis. Skripsi tidak terbit Program Studi Pendidikan Bahasa Indonesia. Universitas Muhammadiyah Mataram Mataram.

Faruk, 2012. Metode Sastra, Ypgyakarta: Pustaka Pelajar.

Ganjarjati, Innayah Nur. Hasrat yang tak Terpenuhi Kajian Psikoanlisis Jacques Lacan dalam Novel Lolita karya Vladimir Nabokow. Hal. 1-83diakses tanggal 29 Maret2018. htt://etd. repository. ugm. ac. id/index. 
php?act=view\&buku id=7592\&mod=peneliti detail\&sub=PenelitiaNDetail\&typ=html

Giyofani Philip 2002. Hasrat Tokoh Utama dalam dalam Kumpulan Cerita Pendek Perempuan yang Mengawini KERIS karya Wayan Sunanrta. Vol. 6, No. 6. 786-797. Diakses tanggal 29 Maret 2018. http://journal. student. uny. ac. id/ojs/index $\mathrm{php} / \mathrm{bsi} /$ article/view/8370

Hill Philip 2002. Lacan untuk pemula. Yogyakarta: Kanisisus

Khaeruddin dan Akib E, 2009. Meteologi Penelitian. Makassar. Lembaga

Perpustakaan dan Penerbitan Universitas Muhammadiyah Makassar.

Mani, Aptifive Ricky. 2016. Hasrat Nano Riantiarno dalam Cermin Cinta:

Kajian Psikoanalisis, Jasques Lacania. Vol No. 2 Diambil Tanggal 29 Maret 2018. https://jurnal. ugm. ac. id/poetika/article/view/15492/11386

Meleong, Lexy J 2001. Meteologi Penelitian Kualitatif. Bandung: Remaja Rodakarya.

Ratna N. K. 2010. Metedologi Penelitian Kajian Budaya dan Ilmu Sosial

Humaniora pada Umumnya. Yogyakarta:Pustaka Belajar.

Semi, Atar, M. 2014. Metode Penelitian Sastra. Bandung: Angkasa . 